\title{
Tumor deposits counted as positive lymph nodes in TNM staging for advanced colorectal cancer: a retrospective multicenter study
}

\author{
Jun $\mathrm{Li}^{1}$, Shengke Yang${ }^{2}$, Junjie Hu${ }^{3}$, Hao Liu ${ }^{4}$, Feng Du${ }^{5}$, Jie Yin ${ }^{6}$, Sai Liu ${ }^{7}, \mathrm{Ci} \mathrm{Li}^{8}$, \\ Shasha Xing ${ }^{9}$, Jiatian Yuan ${ }^{1}$, Bo Lv ${ }^{1}$, Jun Fan ${ }^{1}$, Shusheng Leng ${ }^{1}$, Xin Zhang ${ }^{1}$ and \\ Bing Wang ${ }^{1}$ \\ ${ }^{1}$ General Surgery Department, Affiliated Hospital/Clinical Medical College of Chengdu University, Chengdu, People's Republic \\ of China \\ ${ }^{2}$ General Surgery Department, Sichuan Cancer Hospital/Institution, Chengdu, People's Republic of China \\ ${ }^{3}$ Gastrointestinal Tumor Surgery Department, Hubei Cancer Hospital, Wuhan, People's Republic of China \\ ${ }^{4}$ General Surgery Department, 2nd Affiliated Hospital of Jilin University, Changchun, People's Republic of China \\ ${ }^{5}$ Internal Medicine-Oncology, Cancer Institute/Hospital, Peking Union Medical College and Chinese Academy of Medical \\ Sciences, Beijing, People's Republic of China \\ ${ }^{6}$ General Surgery Department, Xuzhou Central Hospital, Xuzhou, People's Republic of China \\ 7 Surgical Department of Gastrointestinal Diseases, Youan Hospital of Capital Medical University, Beijing, People's Republic \\ of China \\ ${ }^{8}$ Department of Pathology, Affiliated Hospital/Clinical Medical College of Chengdu University, Chengdu, People's Republic of \\ China \\ ${ }^{9}$ Central Laboratory, Affiliated Hospital/Clinical Medical College of Chengdu University, Chengdu, People's Republic of China \\ Correspondence to: Jun Li, email: junl_paper@sina.com
}

Shengke Yang, email: shengkeyang@163.com

Junjie Hu, email: hu2010ky@163.com

Hao Liv, email: yajuhao_ab@163.com

Keywords: colorectal cancer, tumor deposits, lymph nodes

Received: October 20, $2015 \quad$ Accepted: February 13, 2016

Published: February 26, 2016

\section{ABSTRACT}

We investigated the possibility of counting tumor deposits (TDs) as positive lymph nodes ( $\mathrm{pLNs}$ ) in the $\mathrm{pN}$ category and evaluated its prognostic value for colorectal cancer (CRC) patients. A new pN category (npN category) was calculated using the numbers of pLNs plus TDs. The npN category included 4 tiers: npN1a (1 tumor node), npN1b (2-3 tumor nodes), npN2a (4-6 tumor nodes), and npN2b ( $\geq 7$ tumor nodes). We identified 4,121 locally advanced CRC patients, including $717(11.02 \%)$ cases with TDs. Univariate and multivariate analyses were performed to evaluate the diseasefree and overall survival (DFS and OS) for $\mathrm{npN}$ and $\mathrm{pN}$ categories. Multivariate analysis showed that the npN and pN categories were both independent prognostic factors for DFS (HR 1.614, 95\% CI 1.541 to 1.673 ; HR 1.604, 95\% CI 1.533 to 1.679 ) and OS (HR 1.633, 95\% CI 1.550 to 1.720; HR 1.470, 95\% CI 1.410 to 1.532 ). However, the npN category was superior to the $\mathrm{pN}$ category by Harrell's $\mathrm{C}$ statistic. We conclude that it is thus feasible to consider TDs as positive lymph nodes in the pN category when evaluating the prognoses of CRC patients, and the npN category is potentially superior to the TNM (7th edition) PN category for predicting DFS and OS among advanced CRC patients. 


\section{INTRODUCTION}

The TNM staging system for colorectal cancer (CRC) has been changed several times on the basis of a small expert panel consensus. The 5th edition TNM (TNM5) classification was the first to evaluate tumor deposits (TDs) and proposed the 3-mm rule in 1997 [1, 2]. The next edition (TNM6) concerned the presence of TDs in mesorectal and pericolic fat with the primary tumor, and defined TDs as positive lymph nodes (pLNs) when they had the form and smooth contour of lymph nodes (LNs) while irregular TDs with venous invasion remained in the $\mathrm{T}$ category [3, 4]. Recently, the presence of TDs has been reported as an important prognostic factor [5-9].

TDs were again taken into account in the American Joint Committee on Cancer (AJCC) 7th edition TNM classification (TNM7) for CRC, and a new pN1c category was proposed which states that $\mathrm{T} 1$ and $\mathrm{T} 2$ lesions that lack regional positive lymph node(s) but have tumor deposit(s) will be classified in addition as pN1c. However, it is not consistent in that in $\mathrm{pN} 1 \mathrm{c}$ is also an option for $\mathrm{pT} 3 / 4 \mathrm{a}$ tumors in the CRC staging table [10]. Despite the fact that TNM7 states that the number of TDs should be counted according to this categorization strategy, it does not point out the association of the number of TDs with stage III. There are also no clear guidelines on how to classify TDs in patients with pLNs and TDs simultaneously. This potentially impacts the accuracy of the classification and evaluation of the prognosis of CRC patients.

Recently, there has been discussion of the feasibility of TDs being counted as positive lymph nodes in the TNM staging system for CRC. Belt EJ et al. [11] declared lymph node negative CRC (stage II) with TDs should be classified and treated as stage III. Song YX et al. [5] reported that the counting of TDs as pLNs in the TNM staging system is potentially superior to the classification in the TNM7 to assess prognosis and survival for CRC patients. However, both of these studies included small numbers of patients (870 and 513 cases, respectively). In addition, in TNM7 gastric cancer staging, pathologic assessment of the regional pLNs entails their removal and histologic examination to evaluate the total number of nodes and TDs without evidence of residual LN tissue that were considered as pLN [12]. Thus, it is necessary to provide more effective data to validate the feasibility of counting the number of TDs as pLNs in the TNM classification criteria.

Here, we collected large-scale and multicenter data consisting of 4,121 stage II and III CRC patients who received initial radical surgery in order to investigate whether TDs can be counted as metastatic LNs using the AJCC TNM7 staging system for stage III CRC by calculating and comparing the 5-year disease-free survival (DFS) and overall survival (OS).

\section{RESULTS}

A total of 4,456 patients with CRC experienced initial radical surgery. According to the exclusion criteria, 180 cases with pTis/T1 stage, 45 with simultaneous distant metastasis, and 110 with other reasons were excluded. Finally, 4,121 cases were included in this retrospective study.

\section{Clinicopathological characteristics of patients}

In total, we identified $17.4 \%(717 / 4,121)$ of patients with TDs. The male: female ratio was 1.33:1 $(2,352 / 1,769)$. The median age was $58.0 \pm 12.1$ years (range: 14-87). Clinicopathological features are listed in Table 1 . In pN category (7th), the percentages of $\mathrm{pN} 0$ $2 \mathrm{~b}$ were $50.2 \%, 12.9 \%, 13.1 \%, 6.8 \%, 9.1 \%$ and $7.8 \%$, respectively $(P<0.0001)$. By contrast, the percentages of npN0-2b were $50.2 \%, 12.8 \%, 15.3 \%, 12.0 \%$ and $9.7 \%$, respectively $(P<0.0001)$. TDs were associated with preoperative carcinoembryonic antigen (CEA) or carbohydrate antigen 19-9 (CA19-9) levels, pT or pN category, npN category, differentiation grade, pathological category, and histological type (all $P<0.05$ ). Patients with and without TDs were similar with respect to gender, age, tumor location (colon $v s$. rectum), and tumor size (diameter) (all $P>0.05$ ). Additionally, the rates of patients with or without TDs who received adjuvant therapy were $17.0 \%$ and $18.2 \%(P=0.343)$.

\section{TDs resulted in stage migration}

A total of 1,798 TDs were detected in 717 (17.4\%) patients according to the $3-\mathrm{mm}$ (TNM5) and contour (TNM6) rules. The mean TD diameter was $8.5 \pm 3.2 \mathrm{~mm}$ (range: $3-24 \mathrm{~mm}$ ). By changing the definition of TDs to being counted as positive LNs, stage migration was likely to happen. Not surprisingly, the presence of TDs was associated with advanced npN category as compared to $\mathrm{pN}$ category (Table 2). TDs also more often presented with higher pT category (Table 1). In Table 2, we list stage migrations resulting from changes in the definition of TDs. Upstaging occurred in 330 of 717 patients (46.0\%) with TDs that were in the $\mathrm{pN}$ category.

\section{npN as a prognostic factor for DFS and OS}

During follow-up, a total of 1215 patients (29.5\%) suffered failure including 351 (8.5\%) with local recurrence (LR), 973 (23.6\%) with distant metastasis (DM) and 109 (2.6\%) with both LR and DM. The 5-year DFS and OS rates for all 4,121 patients were $69.5 \%$ and $75.2 \%$. The clinical and pathological data including the number of LR, DM, and all failures are listed in Table 2. The 5-year DFS 
Table 1: Association of TDs with clinical and pathological characteristics

\begin{tabular}{|c|c|c|c|c|c|c|}
\hline \multirow{2}{*}{ Variable } & \multicolumn{2}{|c|}{ All Patients $(n=4121)$} & \multicolumn{2}{|c|}{ Patients with TDs $(n=717)$} & \multirow{2}{*}{$X^{2}$} & \multirow{2}{*}{$P$} \\
\hline & \begin{tabular}{|l|} 
No. \\
\end{tabular} & $\%$ & No. & $\%$ & & \\
\hline \multicolumn{7}{|l|}{ Gender } \\
\hline Male & 2352 & 57.1 & 411 & 17.5 & 0.022 & 0.882 \\
\hline Female & 1769 & 42.9 & 306 & 17.3 & & \\
\hline \multicolumn{7}{|l|}{ Age, year } \\
\hline$\leq 60$ & 2312 & 56.1 & 407 & 17.6 & 0.154 & 0.695 \\
\hline$>60$ & 1809 & 43.9 & 310 & 17.1 & & \\
\hline \multicolumn{7}{|c|}{ Tumor location } \\
\hline Colon & 1449 & 35.2 & 278 & 19.2 & 0.51 & 0.475 \\
\hline Rectum & 2671 & 64.8 & 439 & 16.4 & & \\
\hline \multicolumn{7}{|c|}{ Tumor size, diameter } \\
\hline$\leq 5.0 \mathrm{~cm}$ & 2866 & 69.5 & 508 & 17.7 & 0.68 & 0.410 \\
\hline$>5.0 \mathrm{~cm}$ & 1254 & 30.4 & 209 & 16.7 & & \\
\hline \multicolumn{7}{|c|}{ Preoperative CEA levels } \\
\hline$<5.0 \mathrm{ng} / \mathrm{ml}$ & 2479 & 60.2 & 360 & 14.5 & 39.429 & $<0.0001$ \\
\hline$\geq 5.0 \mathrm{ng} / \mathrm{ml}$ & 1161 & 28.2 & 238 & 20.5 & & \\
\hline Unknown & 481 & 11.7 & 119 & 24.7 & & \\
\hline \multicolumn{7}{|c|}{ Preoperative CA199 levels } \\
\hline$<29.0 \mathrm{u} / \mathrm{ml}$ & 2820 & 68.4 & 465 & 16.5 & 8.565 & 0.014 \\
\hline$\geq 29.0 \mathrm{u} / \mathrm{ml}$ & 459 & 11.1 & 101 & 22 & & \\
\hline Unknown & 842 & 20.4 & 151 & 17.9 & & \\
\hline \multicolumn{7}{|c|}{ pT category (7th) } \\
\hline pT 2 & 128 & 3.1 & 4 & 3.1 & 66.154 & $<0.0001$ \\
\hline pT 3 & 2851 & 69.2 & 323 & 11.3 & & \\
\hline pT 4 & 2242 & 54.4 & 390 & 17.4 & & \\
\hline \multicolumn{7}{|c|}{ pN category $(7$ th) } \\
\hline $\mathrm{pN} 0$ & 2070 & 50.2 & 0 & 0 & 61.773 & $<0.0001$ \\
\hline $\mathrm{pN} 1 \mathrm{a}$ & 533 & 12.9 & 100 & 18.8 & & \\
\hline $\mathrm{pN} 1 \mathrm{~b}$ & 539 & 13.1 & 124 & 23 & & \\
\hline $\mathrm{pN} \mathrm{1c}$ & 282 & 6.8 & 282 & 100 & & \\
\hline $\mathrm{pN} 2 \mathrm{a}$ & 374 & 9.1 & 80 & 21.4 & & \\
\hline $\mathrm{pN} 2 \mathrm{~b}$ & 323 & 7.8 & 131 & 40.6 & & \\
\hline \multicolumn{7}{|c|}{ npN category } \\
\hline $\mathrm{npN} 0$ & 2070 & 50.2 & 0 & 0 & 128.185 & $<0.0001$ \\
\hline npN 1a & 526 & 12.8 & 93 & 17.7 & & \\
\hline$n p N 1 b$ & 629 & 15.3 & 214 & 34 & & \\
\hline $\mathrm{npN} 2 \mathrm{a}$ & 495 & 12 & 201 & 40.6 & & \\
\hline $\mathrm{npN} 2 \mathrm{~b}$ & 401 & 9.7 & 209 & 52.1 & & \\
\hline \multicolumn{7}{|c|}{ Venous invasion } \\
\hline Yes & 268 & 6.5 & 87 & 32.5 & 70.306 & $<0.0001$ \\
\hline No & 3853 & 93.5 & 630 & 16.4 & & \\
\hline \multicolumn{7}{|c|}{ Lymphatic invasion } \\
\hline Yes & 26 & 0.6 & 12 & 46.2 & 11.528 & 0.001 \\
\hline No & 4095 & 99.4 & 705 & 17.2 & & \\
\hline \multicolumn{7}{|c|}{ Differentiation grade } \\
\hline Well & 452 & 11 & 43 & 9.5 & 90.633 & $<0.0001$ \\
\hline Moderately & 3213 & 78 & 523 & 16.3 & & \\
\hline Poorly & 456 & 11.1 & 146 & 32 & & \\
\hline
\end{tabular}




\begin{tabular}{|c|c|c|c|c|c|c|}
\hline \multicolumn{7}{|l|}{ Pathological category } \\
\hline $\begin{array}{l}\text { Papillary or tubular } \\
\text { adenocarcinoma }\end{array}$ & 3856 & 93.6 & 660 & 17.1 & 8.991 & 0.003 \\
\hline Mucinous adenocarcinoma & 220 & 5.3 & 38 & 17.3 & & \\
\hline Signet ring cell cancer & 45 & 1.1 & 19 & 42.2 & & \\
\hline \multicolumn{7}{|l|}{ Histological type } \\
\hline Protrude & 2733 & 66.3 & 477 & 17.5 & 17.184 & $<0.0001$ \\
\hline Ulcer & 1151 & 27.9 & 177 & 15.4 & & \\
\hline Infiltrative & 237 & 5.8 & 63 & 26.6 & & \\
\hline \multicolumn{7}{|l|}{ Adjuvant therapy } \\
\hline Yes & 2796 & 67.8 & 476 & 17 & 0.899 & 0.343 \\
\hline No & 1325 & 32.2 & 241 & 18.2 & & \\
\hline
\end{tabular}

Table 2: pN stage migration according to TDs counted as pLNs

\begin{tabular}{|c|c|c|c|c|c|}
\hline \multirow{2}{*}{ pN Category } & \multicolumn{4}{|c|}{ npN Category } & \multirow{2}{*}{ Sum } \\
\hline & npN1a & npN1b & npN2a & npN2b & \\
\hline pN1a & 433 & 74 & 18 & 8 & 533 \\
\hline $\mathrm{pN} 1 \mathrm{~b}$ & & 458 & 63 & 18 & 539 \\
\hline $\mathrm{pN} 1 \mathrm{c}$ & 93 & 97 & 85 & 7 & 282 \\
\hline $\mathrm{pN} 2 \mathrm{a}$ & & & 329 & 45 & 374 \\
\hline $\mathrm{pN} 2 \mathrm{~b}$ & & & & 323 & 323 \\
\hline Sum & 526 & 629 & 495 & 401 & 2051 \\
\hline
\end{tabular}

rates for $\mathrm{npN} 0-2 \mathrm{~b}$ were $83.6 \%, 72.4 \%, 65.6 \%, 45.7 \%$ and $26.0 \%$, respectively $(P<0.0001)$. By contrast, the 5 -year DFS rates for $\mathrm{pN} 0-2 \mathrm{~b}$ were $83.6 \%, 71.4 \%, 57.8 \%, 69.9 \%$, $39.5 \%$, and $25.8 \%$, respectively $(P<0.0001)$. The 5 -year OS for npN0-2b were $87.9 \%, 76.2 \%, 69.1 \%, 57.9 \%$ and $37.1 \%$, respectively $(P<0.0001)$. Compared to the $\mathrm{npN}$ category, the 5 -year OS for $\mathrm{pN} 0-2 \mathrm{~b}$ were $87.9 \%, 74.3 \% \%$, $64.8 \%, 75.2 \%, 50.1 \%$, and $32.9 \%$, respectively $(P<$ $0.0001)$.

Univariate analysis showed that the preoperative CEA or CA199 levels, pT, pN, npN, TDs, venous or lymphatic invasion, differentiation grade, pathological category and histological type were all correlated with DFS and OS (all $P<0.0001$ ). Additionally, age and adjuvant chemotherapy were prognostic factors for OS but not DFS. The DFS and OS curves for both $\mathrm{npN}$ and $\mathrm{pN}$ are shown in Figure 1. Considering the fact that the npN category can be considered as an adjusted classification of the $\mathrm{pN}$ category, making the $\mathrm{pN}$ and $\mathrm{npN}$ categories highly correlated, multivariate models for all patients were calculated separately for each variable to avoid potential bias (Tables 4, 5). As the result, both the $\mathrm{npN}$ and $\mathrm{pN}$ categories were identified as independent prognostic factors for DFS (HR 1.614, 95\% CI 1.541 to 1.673; HR $1.604,95 \%$ CI 1.533 to 1.679 ) and OS (HR $1.633,95 \%$ CI 1.550 to 1.720 ; HR $1.470,95 \%$ CI 1.410 to 1.532 ) by multivariate analyses ( all $P<0.0001$ ).

The $\mathrm{pN}$ and $\mathrm{npN}$ categories were calculated by Harrell's C statistic to identify which one had superior predictive capacity. The $\mathrm{npN}$ category (Harrell's $\mathrm{C}=$ $0.716,95 \%$ CI: 0.709 to 0.728 ) was found to be superior to the $\mathrm{pN}$ category (Harrell's $\mathrm{C}=0.707,95 \% \mathrm{CI}$ : 0.695 to 0.718 ) for DFS. Also, the npN category was a more accurate predictor than $\mathrm{pN}$ category for OS (Harrell's $\mathrm{C}=$ $719,95 \%$ CI: 0.700 to $0.736 ; 712,95 \%$ CI: 0.696 to 0.731 , respectively). To identify whether one TD and one pLN had the same weight in patient outcome, we compared the 5-year DFS and OS rates for patients with pure pLNs with patients with pLNs plus TDs. The results are shown in Table 6 and indicate no prognostic heterogeneity meaning that TDs had the same weight as the pLNs (all $P<0.05$ ).

\section{DISCUSSION}

Changes in definitions of what should be considered as positive lymph nodes (pLNs) and tumor deposits (TDs) have been causing great confusion and having a large impact on patient prognosis and selection for postoperative chemoradiotherapy. Although tumor deposits are defined as focal aggregates of adenocarcinoma located in the pericolic or perirectal fat discontinuous with the primary tumor and unassociated with a lymph node, it is difficult to distinguish TDs and nodes. Thus, TNM5 proposed the $3-\mathrm{mm}$ rule, which defined a tumor nodule $>3 \mathrm{~mm}$ in diameter without histological evidence of residual lymph node tissue as a TD [1]. However, this rule was reported as being based on unpublished data, which were 
Table 3: Influence of different clinical and pathological factors on 5-year DFS and OS

\begin{tabular}{|c|c|c|c|c|c|c|c|c|c|c|c|}
\hline \multirow{2}{*}{ Variable } & \multirow{2}{*}{$\begin{array}{l}\text { No. } \\
\text { of } \\
\text { patients }\end{array}$} & \multicolumn{2}{|c|}{$\begin{array}{l}\text { Local } \\
\text { Recurrence }\end{array}$} & \multicolumn{2}{|c|}{$\begin{array}{l}\text { Distant } \\
\text { Metastasis }\end{array}$} & \multicolumn{2}{|c|}{ All Failure } & \multirow{2}{*}{$\begin{array}{l}\text { 5-Years } \\
\text { DFS } \\
\text { Rate }\end{array}$} & \multirow{2}{*}{$P$} & \multirow{2}{*}{$\begin{array}{l}\text { 5-Year } \\
\text { OS Rate }\end{array}$} & \multirow{2}{*}{$P$} \\
\hline & & No. & $\%$ & No. & $\%$ & No. & $\%$ & & & & \\
\hline & 4121 & 351 & $8.5 \%$ & 973 & $23.6 \%$ & 1215 & $29.5 \%$ & $69.5 \%$ & & $75.2 \%$ & \\
\hline \multicolumn{12}{|l|}{ Gender } \\
\hline Male & 2352 & 219 & $9.3 \%$ & 553 & $23.5 \%$ & 713 & $30.3 \%$ & $68.7 \%$ & 0.081 & $74.9 \%$ & 0.762 \\
\hline Female & 1769 & 132 & $7.5 \%$ & 420 & $24.7 \%$ & 502 & $29.4 \%$ & $70.6 \%$ & & $75.5 \%$ & \\
\hline \multicolumn{12}{|l|}{ Age, year } \\
\hline$\leq 60$ & 2312 & 173 & $7.5 \%$ & 535 & $24.1 \%$ & 652 & $29.2 \%$ & $71.5 \%$ & 0.087 & $78.0 \%$ & $<0.0001$ \\
\hline$>60$ & 1809 & 178 & $9.8 \%$ & 438 & $24.2 \%$ & 563 & $31.1 \%$ & $66.9 \%$ & & $71.5 \%$ & \\
\hline \multicolumn{12}{|c|}{\begin{tabular}{|l|} 
Tumor location \\
\end{tabular}} \\
\hline Colon & 1449 & 34 & $2.3 \%$ & 364 & $25.1 \%$ & 381 & $26.3 \%$ & $73.2 \%$ & 0.065 & $76.1 \%$ & 0.132 \\
\hline Rectum & 2671 & 317 & $11.9 \%$ & 609 & $22.8 \%$ & 834 & $31.2 \%$ & $67.4 \%$ & & $74.7 \%$ & \\
\hline \multicolumn{12}{|c|}{ Tumor size, diameter } \\
\hline$\leq 5.0 \mathrm{~cm}$ & 2866 & 240 & $8.4 \%$ & 670 & $23.4 \%$ & 835 & $29.1 \%$ & $70.1 \%$ & 0.654 & $75.8 \%$ & 0.251 \\
\hline$>5.0 \mathrm{~cm}$ & 1254 & 111 & $8.9 \%$ & 303 & $24.1 \%$ & 380 & $30.3 \%$ & $68.2 \%$ & & $73.9 \%$ & \\
\hline \multicolumn{12}{|c|}{$\begin{array}{l}\text { Preoperative CEA } \\
\text { levels }\end{array}$} \\
\hline$<5.0 \mathrm{ng} / \mathrm{ml}$ & 2479 & 98 & $8.4 \%$ & 463 & $18.7 \%$ & 610 & $24.6 \%$ & $75.0 \%$ & $<0.0001$ & $80.7 \%$ & $<0.0001$ \\
\hline$\geq 5.0 \mathrm{ng} / \mathrm{ml}$ & 1161 & 198 & $8.0 \%$ & 401 & $34.5 \%$ & 454 & $39.1 \%$ & $58.6 \%$ & & $64.3 \%$ & \\
\hline Unknown & 481 & 55 & $11.4 \%$ & 109 & $22.7 \%$ & 151 & $31.4 \%$ & $67.0 \%$ & & $72.0 \%$ & \\
\hline \multicolumn{12}{|c|}{$\begin{array}{l}\text { Preoperative CA199 } \\
\text { levels }\end{array}$} \\
\hline$<29.0 \mathrm{u} / \mathrm{ml}$ & 2820 & 32 & $7.0 \%$ & 490 & $20.8 \%$ & 601 & $26.5 \%$ & $73.1 \%$ & $<0.0001$ & $81.3 \%$ & $<0.0001$ \\
\hline$\geq 29.0 \mathrm{u} / \mathrm{ml}$ & 459 & 169 & $7.2 \%$ & 179 & $39.0 \%$ & 195 & $42.5 \%$ & $54.9 \%$ & & $54.5 \%$ & \\
\hline Unknown & 842 & 55 & $6.5 \%$ & 109 & $12.9 \%$ & 151 & $17.9 \%$ & $80.2 \%$ & & $72.0 \%$ & \\
\hline \multicolumn{12}{|c|}{ pT category $(7$ th) } \\
\hline pT 2 & 128 & 8 & $6.2 \%$ & 20 & $15.6 \%$ & 26 & $20.3 \%$ & $78.5 \%$ & $<0.0001$ & $82.8 \%$ & $<0.0001$ \\
\hline pT 3 & 2851 & 141 & $8.1 \%$ & 253 & $14.4 \%$ & 353 & $20.2 \%$ & $79.2 \%$ & & $83.4 \%$ & \\
\hline pT 4 & 2242 & 202 & $9.0 \%$ & 700 & $31.2 \%$ & 836 & $37.3 \%$ & $61.3 \%$ & & $68.1 \%$ & \\
\hline \multicolumn{12}{|c|}{ pN category $(7$ th) } \\
\hline $\mathrm{pN} 0$ & 2070 & 106 & $5.1 \%$ & 252 & $12.2 \%$ & 332 & $16.0 \%$ & $83.6 \%$ & $<0.0001$ & $87.9 \%$ & $<0.0001$ \\
\hline $\mathrm{pN} 1 \mathrm{a}$ & 533 & 39 & $7.3 \%$ & 121 & $22.7 \%$ & 149 & $28.0 \%$ & $71.4 \%$ & & $74.3 \%$ & \\
\hline $\mathrm{pN} 1 \mathrm{~b}$ & 539 & 43 & $8.0 \%$ & 187 & $34.7 \%$ & 215 & $39.1 \%$ & $57.8 \%$ & & $64.8 \%$ & \\
\hline $\mathrm{pN} 1 \mathrm{c}$ & 282 & 42 & $14.9 \%$ & 47 & $16.7 \%$ & 87 & $30.9 \%$ & $69.9 \%$ & & $75.2 \%$ & \\
\hline $\mathrm{pN} 2 \mathrm{a}$ & 374 & 56 & $15.0 \%$ & 171 & $45.7 \%$ & 207 & $55.3 \%$ & $39.5 \%$ & & $50.1 \%$ & \\
\hline $\mathrm{pN} 2 \mathrm{~b}$ & 323 & 65 & $20.1 \%$ & 195 & $40.6 \%$ & 225 & $69.7 \%$ & $25.8 \%$ & & $32.9 \%$ & \\
\hline \multicolumn{12}{|c|}{$\mathrm{npN}$ category } \\
\hline npN 0 & 2070 & 106 & $5.1 \%$ & 252 & $12.2 \%$ & 332 & $16.0 \%$ & $83.6 \%$ & $<0.0001$ & $87.9 \%$ & $<0.0001$ \\
\hline npN 1a & 526 & 32 & $6.1 \%$ & 116 & $22.1 \%$ & 141 & $26.8 \%$ & $72.4 \%$ & & $76.2 \%$ & \\
\hline $\mathrm{npN} 1 \mathrm{~b}$ & 629 & 51 & $8.1 \%$ & 179 & $28.5 \%$ & 207 & $22.9 \%$ & $65.6 \%$ & & $69.1 \%$ & \\
\hline $\mathrm{npN} 2 \mathrm{a}$ & 495 & 72 & $14.5 \%$ & 198 & $40.0 \%$ & 252 & $50.9 \%$ & $45.7 \%$ & & $57.9 \%$ & \\
\hline $\mathrm{npN} 2 \mathrm{~b}$ & 401 & 90 & $22.4 \%$ & 228 & $56.9 \%$ & 283 & $60.6 \%$ & $26.0 \%$ & & $37.1 \%$ & \\
\hline
\end{tabular}




\begin{tabular}{|l|l|l|l|l|l|l|l|l|l|l|l|}
\hline Tumor deposits (TDs) & & & & & & & & & & & \\
\hline Positive & 717 & 131 & $18.3 \%$ & 281 & $39.2 \%$ & 389 & $54.3 \%$ & $44.6 \%$ & $<0.0001$ & $57.7 \%$ & $<0.0001$ \\
\hline Negative & 3404 & 220 & $6.5 \%$ & 692 & $20.3 \%$ & 826 & $24.3 \%$ & $74.9 \%$ & & $78.9 \%$ & \\
\hline Venous invasion & & & & & & & & & & & \\
\hline Yes & 268 & 47 & $17.5 \%$ & 136 & $50.7 \%$ & 157 & $58.6 \%$ & $36.8 \%$ & $<0.0001$ & $45.7 \%$ & $<0.0001$ \\
\hline No & 3853 & 304 & $7.9 \%$ & 837 & $21.7 \%$ & 1058 & $27.5 \%$ & $71.7 \%$ & & $77.1 \%$ & \\
\hline Lymphatic invasion & & & & & & & & & & & \\
\hline Yes & 26 & 8 & $30.8 \%$ & 10 & $38.5 \%$ & 16 & $61.5 \%$ & $29.2 \%$ & $<0.0001$ & $35.6 \%$ & $<0.0001$ \\
\hline No & 4095 & 343 & $9.4 \%$ & 963 & $23.5 \%$ & 1199 & $29.3 \%$ & $69.8 \%$ & & $75.4 \%$ & \\
\hline Differentiation grade & & & & & & & & & & & \\
\hline Well & 452 & 22 & $4.9 \%$ & 54 & $11.9 \%$ & 73 & $16.2 \%$ & $82.7 \%$ & $<0.0001$ & $88.2 \%$ & $<0.0001$ \\
\hline Moderately & 3213 & 275 & $8.6 \%$ & 725 & $22.6 \%$ & 922 & $28.7 \%$ & $70.4 \%$ & & $75.8 \%$ & \\
\hline Poorly & 456 & 54 & $11.8 \%$ & 194 & $42.5 \%$ & 220 & $48.2 \%$ & $50.0 \%$ & & $57.8 \%$ & \\
\hline Pathological category & & & & & & & & & & & \\
\hline $\begin{array}{l}\text { Papillary or tubular } \\
\text { adenocarcinoma }\end{array}$ & 3856 & 325 & $8.4 \%$ & 888 & $23.0 \%$ & 1121 & $29.1 \%$ & $69.9 \%$ & $<0.0001$ & $75.9 \%$ & $<0.0001$ \\
\hline $\begin{array}{l}\text { Mucinous } \\
\text { adenocarcinoma }\end{array}$ & 220 & 20 & $9.1 \%$ & 63 & $28.6 \%$ & 68 & $30.9 \%$ & $68.2 \%$ & & $70.1 \%$ & \\
\hline Signet ring cell cancer & 45 & 6 & $13.7 \%$ & 22 & $49.9 \%$ & 26 & $57.8 \%$ & $40.8 \%$ & & $41.5 \%$ & \\
\hline Histological type & & & & & & & & & & & \\
\hline Protrude & 2733 & 230 & $8.4 \%$ & 561 & $20.5 \%$ & 722 & $26.4 \%$ & $73.0 \%$ & $<0.0001$ & $78.5 \%$ & $<0.0001$ \\
\hline Ulcer & 1151 & 98 & $8.5 \%$ & 322 & $28.0 \%$ & 386 & $33.5 \%$ & $64.8 \%$ & & $70.1 \%$ & \\
\hline Infiltrative & 237 & 23 & $9.7 \%$ & 90 & $38.0 \%$ & 107 & $45.1 \%$ & $52.1 \%$ & & $61.2 \%$ & \\
\hline Adjuvant therapy & & & & & & & & & & & \\
\hline Yes & 2796 & 228 & $8.2 \%$ & 672 & $24.0 \%$ & 825 & $29.5 \%$ & $70.1 \%$ & 0.361 & $76.7 \%$ & 0.002 \\
\hline No & 123 & $9.3 \%$ & 301 & $22.7 \%$ & 390 & $29.4 \%$ & $68.2 \%$ & & $71.8 \%$ & \\
\hline
\end{tabular}

Table 4: Multivariate analysis for 5-year DFS and OS when $\mathrm{npN}$ category enrolled

\begin{tabular}{|l|l|l|l|l|l|l|}
\hline \multirow{2}{*}{ Variables } & \multicolumn{4}{l}{ 5-Year DFS } & 5-Year OS & \\
\cline { 2 - 7 } & HR & $\mathbf{9 5 . 0} \%$ CI & $\boldsymbol{P}$ & HR & $\mathbf{9 5 . 0 \%}$ CI & $\boldsymbol{P}$ \\
\hline Age & - & - & - & 1.346 & $(1.160$ to 1.563$)$ & $<0.0001$ \\
\hline Preoperative CEA & 0.901 & $(0.793$ to 1.023$)$ & 0.108 & 0.950 & $(0.822$ to 1.099$)$ & 0.493 \\
\hline Preoperative CA199 & 0.976 & $(0.837$ to 1.138$)$ & 0.755 & 0.839 & $(0.709$ to 0.993$)$ & 0.041 \\
\hline pT category & 1.448 & $(1.270$ to 1.651$)$ & 0.000 & 1.517 & $(1.300$ to 1.769$)$ & $<0.0001$ \\
\hline npN category & 1.519 & $(1.444$ to 1.598$)$ & $<0.0001$ & 1.653 & $(1.560$ to 1.752$)$ & $<0.0001$ \\
\hline TDs & 0.665 & $(0.570$ to 0.775$)$ & $<0.0001$ & 1.108 & $(1.007$ to 1.202$)$ & 0.032 \\
\hline Venous invasion & 0.730 & $(0.595$ to 0.897$)$ & 0.003 & 0.791 & $(0.629$ to 0.995$)$ & 0.045 \\
\hline Lymphatic invasion & 0.466 & $(0.283$ to 0.769$)$ & 0.003 & 0.534 & $(0.311$ to 0.917$)$ & 0.023 \\
\hline Differentiation grade & 1.333 & $(1.163$ to 1.529$)$ & $<0.0001$ & 1.384 & $(1.187$ to 1.613$)$ & $<0.0001$ \\
\hline Pathological category & 1.094 & $(0.989$ to 1.210$)$ & 0.082 & 1.140 & $(1.108$ to 1.277$)$ & 0.023 \\
\hline Histological type & 0.936 & $(0.784$ to 1.117$)$ & 0.463 & 1.139 & $(0.947$ to 1.371$)$ & 0.168 \\
\hline Adjuvant Chemotherapy & - & - & - & 1.747 & $(1.488$ to 2.052$)$ & $<0.0001$ \\
\hline
\end{tabular}

not substantiated. In TNM6, the new definition of TDs based on contour replaced the $3-\mathrm{mm}$ rule, and defined TDs to be classified as pLNs when they had the form and smooth contour of lymph nodes, while irregular TDs were classified in the $\mathrm{pT}$ category and as venous invasion [3]. Still, this contour rule lacks support from clinical 
Table 5: Multivariate analysis for 5-year DFS and OS when pN category enrolled

\begin{tabular}{|l|l|l|l|l|l|l|}
\hline \multirow{2}{*}{ Variables } & $\mathbf{5}$-Year DFS & \multicolumn{3}{l|}{ 5-Year $\mathbf{O S}$} \\
\cline { 2 - 7 } & HR & $\mathbf{9 5 . 0} \%$ CI & $\boldsymbol{P}$ & HR & $\mathbf{9 5 . 0 \%}$ CI & $\boldsymbol{P}$ \\
\hline Age & - & - & - & 1.371 & $(1.181$ to 1.592$)$ & $<0.0001$ \\
\hline Preoperative CEA & 0.901 & $(0.792$ to 1.024$)$ & 0.111 & 0.970 & $(0.837$ to 1.123$)$ & 0.683 \\
\hline PreoperativeCA199 & 0.987 & $(0.844$ to 1.154$)$ & 0.867 & 0.843 & $(0.711$ to 0.994$)$ & 0.041 \\
\hline pT category & 1.461 & $(1.280$ to 1.668$)$ & $<0.0001$ & 1.533 & $(1.312$ to 1.791$)$ & $<0.0001$ \\
\hline pN category & 1.367 & $(1.313$ to 1.422$)$ & $<0.0001$ & 1.462 & $(1.398$ to 1.529$)$ & $<0.0001$ \\
\hline TDs & 0.591 & $(0.509$ to 0.687$)$ & $<0.0001$ & 1.103 & $(1.039$ to 1.200$)$ & 0.036 \\
\hline Venous invasion & 0.729 & $(0.594$ to 0.895$)$ & 0.003 & 0.816 & $(0.648$ to 1.027$)$ & 0.083 \\
\hline Lymphatic invasion & 0.455 & $(0.276$ to 0.750$)$ & 0.002 & 0.555 & $(0.323$ to 0.954$)$ & 0.033 \\
\hline Differentiation grade & 1.387 & $(1.209$ to 1.591$)$ & $<0.0001$ & 1.425 & $(1.222$ to 1.663$)$ & $<0.0001$ \\
\hline Pathological category & 1.112 & $(1.006$ to 1.229$)$ & 0.037 & 1.160 & $(1.036$ to 1.298$)$ & 0.010 \\
\hline Histological type & 0.924 & $(0.774$ to 1.103$)$ & 0.381 & 1.131 & $(0.940$ to 1.361$)$ & 0.193 \\
\hline Adjuvant Chemotherapy & - & - & - & 1.660 & $(1.413$ to 1.950$)$ & $<0.0001$ \\
\hline
\end{tabular}

Table 6: Influence of TDs on 5-year DFS and OS in subgroups of npN category

\begin{tabular}{|c|c|c|c|c|c|c|c|}
\hline \multirow{2}{*}{$\begin{array}{l}\text { npN } \\
\text { Category }\end{array}$} & \multirow{2}{*}{$\begin{array}{l}\text { No. of All } \\
\text { Patients }\end{array}$} & \multicolumn{2}{|c|}{$\begin{array}{l}\text { All Failure } \\
\text { with TDs }\end{array}$} & \multicolumn{2}{|c|}{\begin{tabular}{|l|} 
All Failure \\
without TDs
\end{tabular}} & \multirow{2}{*}{$\begin{array}{l}\text { 5-Years DFS } \\
\text { Rate }\end{array}$} & \multirow{2}{*}{$\begin{array}{ll}\text { 5-Years } & \text { OS } \\
\text { Rate }\end{array}$} \\
\hline & & No. & $\%$ & No. & $\%$ & & \\
\hline$n p N 1 a$ & 526 & 27 & $29.00 \%$ & 114 & $26.30 \%$ & $72.1 \%$ vs. $73.6 \%$ & $76.0 \%$ vs. $76.2 \%$ \\
\hline npN 1b & 629 & 73 & $34.10 \%$ & 134 & $32.30 \%$ & $65.4 \%$ vs. $65.7 \%$ & $68.9 \%$ vs. $69.9 \%$ \\
\hline $\mathrm{npN} 2 \mathrm{a}$ & 495 & 107 & $53.20 \%$ & 145 & $49.30 \%$ & $44.8 \%$ vs. $46.3 \%$ & $57.3 \%$ vs. $58.5 \%$ \\
\hline$n p N 2 b$ & 401 & 150 & $71.80 \%$ & 133 & $69.30 \%$ & $25.4 \%$ vs. $27.6 \%$ & $36.8 \%$ vs. $37.5 \%$ \\
\hline
\end{tabular}

Note: the 5-year DFS rates of the subgroups with or without TDs in npN1a, 1b, 2a, $2 \mathrm{~b}$ were similar (all $P<0.05$ ), and the 5-year OS rates of the subgroups had the similar results $($ all $P<0.05)$.

evidences and reproducibility is poor because of the absence of appropriate guidelines [8].

Currently, the TNM7 proposed a novel $\mathrm{pN}$ category $(\mathrm{pN} 1 \mathrm{c})$ in stage III in the absence of lymph node (LN) metastasis which states $\mathrm{T} 1$ and T2 lesions that lack regional positive lymph node(s) but have tumor deposit(s) be classified in addition as $\mathrm{pN} 1 \mathrm{c}$, though it is not consistent in that in $\mathrm{pN} 1 \mathrm{c}$ is also an option for $\mathrm{pT} 3 / 4 \mathrm{a}$ tumors in the CRC staging table [10]. However, this new edition does not propose guidelines on the definition of TDs, which might impact reproducibility because of subjective opinion from pathologists. Although the TNM staging system changed several times with lack of appropriate guidelines, it is still the most important determinant of prognosis in $\mathrm{CRC}$ and it is the basis for the patient management guidelines that influence most patient management decisions [5].

The prevalence of TDs ranges from $6 \%$ to $64 \%$ in CRC and $17 \%$ to $55 \%$ in colon cancer [13]. The TNM7 abandoned the $3-\mathrm{mm}$ rule and retained the contour rule so that classification of TDs is left to the discretion of the pathologists and $\mathrm{pN} 1 \mathrm{c}$ is designated for TDs. However, when we investigated the use of the new definition for TDs, we found that all studies selected TDs depending, in part, on the definition. In other words, TDs selection is still lacking in guidelines. Still, it is difficult to distinguish pLNs and TDs especially when nodes are replaced completely by tumor cells. In fact, the TNM7 gastric cancer staging system has considered TDs as metastatic lymph nodes and the number of TDs was included for pathologic staging [12]. Additionally, TDs were considered as pLNs in Japanese classification of CRC [14]. Song YX et al [5] declared that tumor deposits can be counted as metastatic lymph nodes in TNM staging system for CRC. Based on the above evidence, we attempted to consider all TDs as pLNs and re-designate the $\mathrm{pN}$ category.

In the present study, we considered all TDs as pLNs and the $n p N$ category was determined by the number of pLNs plus TDs. By using the $n p N$ category, we simplified the node category and investigated the feasibility and effects. The 5-year DFS and OS rates of patients with or without TDs were $44.6 \%$ vs. $74.9 \%$ and $57.7 \%$ vs. $78.9 \%$ ( $P<0.0001$, respectively), which indicatapproved that patients with TDs had a worse DFS and OS compared with patients without TDs. This result was similar with to a previous study [8]. By using univariateble and multivariateble analyses, we concluded that TDs could be potentially an independent and adverse prognostic factor for colorectal cancer. Of note, in multivariable analysis, we found that both the $\mathrm{npN}$ and $\mathrm{pN}$ category were 
independent predictors for long-term outcome, including DFS and OS in CRC. And then we declared that, however, the $\mathrm{npN}$ category was superior to the $\mathrm{pN}$ category for DFS (Harrell's C $=0.716,95 \%$ CI: 0.709 to 0.728 vs. 0.707 , 95\% CI: 0.695 to 0.718 ) and OS (Harrell's C $=719,95 \%$ CI: 0.700 to $0.736 v s$. $0.712,95 \%$ CI: 0.696 to 0.731 ). Thus, we proposed that the TDs can be counted as pLNs in TNM staging system and the $n p N$ category is feasible and superior to the $\mathrm{pN}$ category for predicting the long-term outcomes in CRC.

The origins of TDs remain controversial. Some studies propose that 3 types of TDs can be identified. They define TDs as "vascular invasion type," "TDs other than the vascular invasion type," and "tumor deposits, extramural venous and perineural types of invasion" [15, 16]. Recent studies have declared strong correlations between the presence of TDs and vascular invasion $[7,17$, 18]. However, in the present study, we did not differentiate between types of TDs and reported that $32.5 \%$ (87/268) of the TDs was with venous invasion, which was lower than previous studies. Besides, 46.2\% (12/26) of the patients with TDs also had lymphatic invasion. In our study, we differentiated venous invasion from lymphatic invasion by hematoxylin-eosin (H-E) staining, which may reduce the accuracy of recognizing venous and lymphatic invasion. In fact, many other factors such as the histological sectioning, which is only a 2-demensional sample of the 3-demensional structure, could cause us to underestimate the association of TDs with vessels.

Whether or not TDs should be considered pLNs or satellite tumor nodules for the purposes of staging may be difficult to determine. It is thus necessary and reasonable to consider TDs as pLNs. Using the $n p N$ category, pathologists and clinicians can simplify the TNM staging system and make suitable suggestions for patient postoperative treatment.

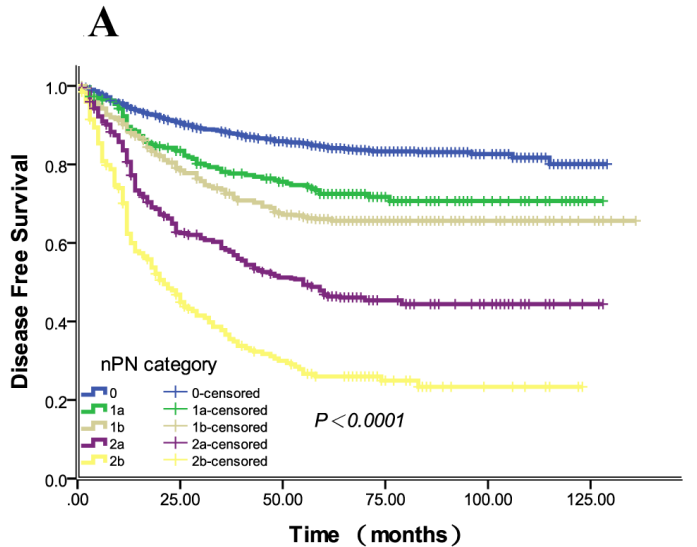

B

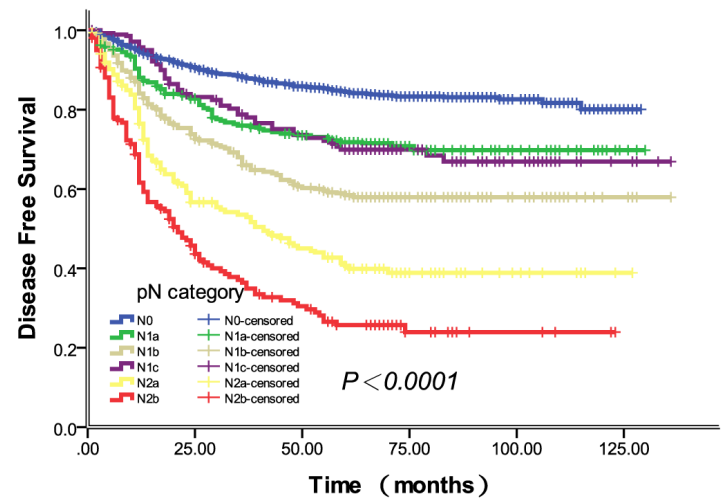

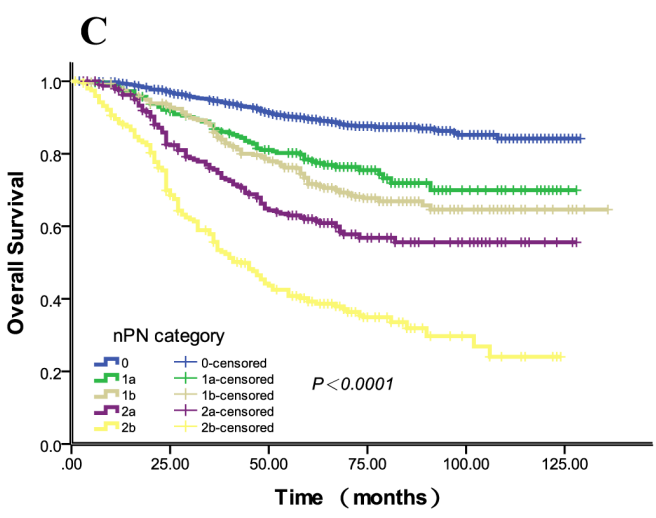

D

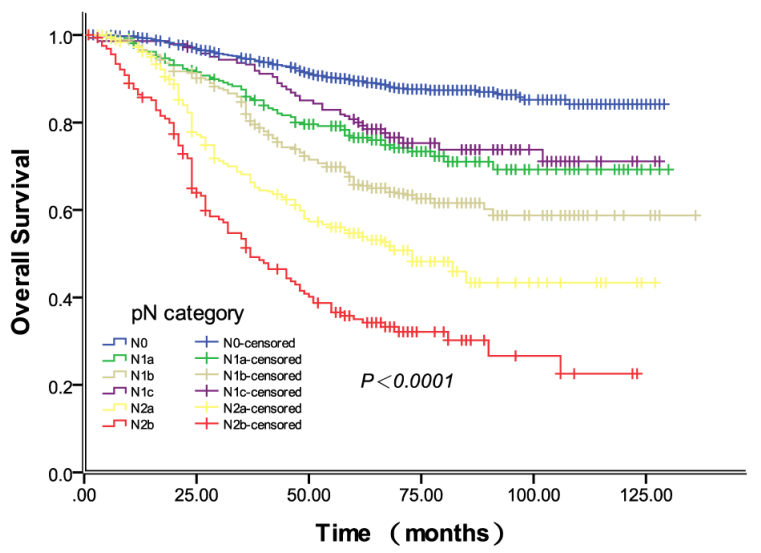

Figure 1: The DFS and OS curves for npN and pN categories. 1A. The 5-year DFS rates of npN0-2b were $83.6 \%, 72.4 \%$, $65.6 \%, 45.7 \%, 26.0 \%$,respectively $(P<0.0001)$, and the 5-year DFS rates of each group from npN 0 to $2 \mathrm{~b}$ were different (all $P<0.05)$. 1B. The 5-year DFS rates of pN0-2b were $83.6 \%, 71.4 \%, 57.8 \%, 69.9 \%, 39.5 \%$, and $25.8 \%$, respectively $(P<0.0001)$. pN1a and $1 \mathrm{c}$ had similar 5-year DFS rates $(P=0.862)$. 1C. The 5-year OS rates of npN0-2b were $87.9 \%, 76.2 \%, 69.1 \%, 57.9 \%$ and $37.1 \%$, respectively $(P$ $<0.0001$ ), and the 5-year DFS rates of each group from npN 0 to $2 \mathrm{~b}$ were different (all $P<0.05$ ). 1D. The 5-year OS rates of pN0-2b were $87.9 \%, 74.3 \%, 64.8 \%, 75.2 \%, 50.1 \%$ and $32.9 \%$, respectively $(P<0.0001)$, and the 5 -year DFS rates of each group from pN 0 to $2 \mathrm{~b}$ were different (all $P<0.05)$. Of note, pN1c had a similar 5-year OS rate with pN1a $(P=0.303)$. 
The results from this study are constrained by all the flaws and biases inherent to a nonrandomized trial, although this study included large-scale and multicenter data. Additionally, there are no clear and regular guidelines on how to identify the TDs from lymph nodes, which also may potentially influence the conclusions. The ideal trial design to investigate TDs according to sections of whole specimens would be a prospective clinical trial, which may be helpful to get more reliable data.

In sum, we found that it was feasible to consider TDs as positive lymph nodes in the $\mathrm{pN}$ category for evaluating the prognoses of CRC patients, and the $n p N$ category was potentially superior to the 7 th $\mathrm{pN}$ category for predicting the disease-free and overall survival of advanced CRC patients. Whether the $\mathrm{npN}$ category has any additional significant practical impact on patients management needs more data to validate.

\section{PATIENTS AND METHODS}

\section{Ethics considerations}

Ethical approval was obtained from the appropriate ethics committees of all participating study sites before the enrolment of patients started. Informed consent was obtained by the investigator at each center from all patients before patient enrollment.

\section{Patients}

A total of 4,121 patients with stage II and III colorectal adenocarcinoma who received an initial radical surgery were identified at seven study centers in China between January 2004 and December 2011, and all relevant data were retrospectively collected including age, gender, serum CEA and CA199 levels, date of surgery, location of the primary tumor (colon and rectal), date and site of recurrence, pathological result, adjuvant chemoradiotherapy and cause of death (CRC related or other cause). We defined colon cancer including tumors locating in cecum to sigmoid colon, and rectal cancer containing tumors locating in rectum or rectosigmoid junction according to the definition from Chok KS et al. [19].

The exclusion criteria were as follows: 1) patients who received neoadjuvant chemoradiotherapy (NCRT, resulting in less nodes detection in specimens); 2) patients with distant metastasis such as liver metastasis found pre- or perioperatively; 3) patients with multiple adenocarcinomas of colon and rectum; 4) patients with synchronous or metachronous tumors; 5) patients who had suffered from colorectal cancer before; 6) patients who died in the immediate postoperative period (within 1 month); 7) patients with positive circumferential resection margins; and 8) patients without complete pathological slides.

\section{Treatments}

All patients initially received $\mathrm{R} 0$ resection without preoperative radiotherapy and/or chemotherapy. For rectal cancer patients, the standard total mesorectal excision was performed. After surgery, patients were treated with radiotherapy and/or chemotherapy or not according to body situation and TNM staging system except some patients who rejected adjuvant therapy. Patients with rectal cancer received adjuvant chemoradiotherapy (40-50Gy/2Gy/20-25F and Xeloda basically), while colon cancer patients were treated with Xeloda and 5-Fu regimens basically. 1325 patients did not received adjuvant therapy, including $83.1 \%(1101 / 1325)$ of patients who were in low risk, and other $16.9 \%(224 / 1325)$ who were in high risk (venous invasion, lymphatic invasion, poor differentiation, or advanced stage) but rejected adjuvant therapy $(46.4 \%, 104 / 224)$, or were in poor body situation and could not tolerate adjuvant therapy $(53.6 \%, 120 / 224)$.

\section{Pathologic examination}

Sections from all resected specimens were examined by local pathologists from seven hospitals. The standardized protocol included determination of the AJCC TNM classification, stage grouping, differentiation degree, histological type, pathological number of examined and involved lymph nodes, and presence or absence of lymphatic or venous invasion. All slides were reviewed for the presence of TDs, defined as either macroscopic or microscopic depositions of carcinoma, without any residual lymph node structures. TDs were assessed using the $3-\mathrm{mm}$ (TNM5) and contour (TNM6) rules [7, 8]. For a regular tumor nodule, we classify it as a positive LN. For an irregular node without any residual tissues of LN we consider it as a TD if the diameter $>3 \mathrm{~mm}$ measured by a ruler, otherwise, we consider the irregular node as pT3 if the diameter $\leq 3 \mathrm{~mm}$. The reference pathologist tested pathological sections and then recorded the findings in a standardized document.

\section{Classification methods}

All patients were classified depending on TNM7, and then we counted TDs as pLNs in a new pN category. In this study, the $\mathrm{pN}$ category which combined with the number of TDs was recorded as $\mathrm{npN}$ category [5]. 


\section{Follow-up}

The follow-up result was collected from all seven hospitals'database. The end point of follow-up was May 2015. The median time of follow-up was 66 months (range: 2-136 months).

\section{Statistical analysis}

Local recurrence and distant metastasis analyses were performed for all eligible patients who received R0 resection without distant metastasis found at time of surgery. All time-to-event end points were measured from date of radical surgery. Disease-free survival (DFS) and overall survival (OS) was calculated from radical resection to finding evidence of local recurrence and/or distant metastasis. Statistical analysis was performed using SPSS software (version 19). Differences were evaluated with the log-rank test. Analyses for local recurrence and distant metastasis were calculated as cumulative incidences. Mutivariate models were performed using the Cox proportional hazards model. All significant variables in the univariate analysis were included in multivariate Cox regression models in a forward-step procedure. The variables were entered in the order according to clinical relevance into the regression models with increasing complexity, and significance was assessed using analysis of variance analysis. The predictive power of the individual models was evaluated using Harrell'C statistic. A model with perfect predictive capacity (sensitivity and specificity of $100 \%$ ) would have a Harrell'C statistic of 1.00 and the highest Harrell' $\mathrm{C}$ statistic was chosen as the best model [20]. A two-sided $p$ value less than 0.05 was considered to be significant.

\section{Authors' contributions}

JL, SKY, JJH, and HL conceived of and designed the study. JL, SKY, HL, JJH, FD, JY, SL, CL, JF, SSL, $\mathrm{XZ}, \mathrm{BW}, \mathrm{JTY}$ and BL provided study materials or patients. JL, SSX, and SKY performed the analyses. JL, SL and FD prepared all figures and tables. JL, HL, SKY and JJH wrote the main manuscript. All authors reviewed the manuscript.

\section{CONFLICTS OF INTEREST}

None of the authors have any conflicts of interest to declare.

\section{REFERENCES}

1. Sobin LH, Wittekind C (eds): International Union Against Cancer TNM Classification of Malignant Tumours (ed 5).
Hoboken, NJ, John Wiley \& Sons, 1997.

2. Fleming ID, Cooper JS, Henson DE (eds): AJCC Cancer Staging Manual (ed 5). Philadelphia, PA, Lippincott Raven, 1998.

3. Sobin LH, Wittekind C (eds): International Union Against Cancer TNM Classification of Malignant Tumours (ed 6). Hoboken, NJ, John Wiley \& Sons, 2002

4. Greene FL, Page DL, Fleming ID (eds): AJCC Staging Handbook (ed 6). New York, NY, Springer, 2002.

5. Song YX, Gao P, Wang ZN, Liang JW, Sun Z, Wang MX, Dong YX, Wang XF, Xu HM. Can the tumor deposits be counted as metastatic lymph nodes in the UICC TNM staging system for colorectal cancer? PLoS One. 2012; 7:e34087.

6. Lin Q, Wei Y, Ren L, Zhong Y, Qin C, Zheng P, Xu $\mathrm{P}, \mathrm{Zhu} \mathrm{D}$, Ji M, Xu J. Tumor deposit is a poor prognostic indicator in patients who underwent simultaneous resection for synchronous colorectal liver metastases. Onco Targets Ther. 2015; 22:233-40.

7. Nagtegaal ID, Tot T, Jayne DG, McShane P, Nihlberg A, Marshall HC, Pahlman L, Brown JM, Guillou PJ, Quirke P. Lymph nodes, tumor deposits, and TNM: are we getting better? J Clin Oncol. 2011; 29:2487-92.

8. Nagtegaal ID, Quirke P. Colorectal tumour deposits in the mesorectum and pericolon: a critical review. Histopathology. 2007; 51:141-9.

9. Tateishi S, Arima S, Futami K, Kawahara K, Tachikawa D, Naritomi K, Iwashita A. A clinicopathological investigation of "tumor nodules" in colorectal cancer. Surg Today. $2005 ; 35: 377-84$.

10. Sobin LH, Gospodarowicz MK, Wittekind C (2010). TNM classification of malignant tumours, 7th edition.

11. Belt EJ, van Stijn MF, Bril H, de Lange-de Klerk ES, Meijer GA, Meijer S, Stockmann HB. Lymph node negative colorectal cancers with isolated tumor deposits should be classified and treated as stage III. Ann Surg Oncol. 2010; 17:3203-11.

12. Edge SB, Byrd DR, Compton CC, Fritz AG, Greene FL (eds). AJCC cancer staging handbook, 7th edition. New York: Springer. 149 p, 2010.

13. Ono $\mathrm{C}$, Yoshinaga $\mathrm{K}$, Enomoto $\mathrm{M}$, Sugihara $\mathrm{K}$. Discontinuous rectal cancer spread in the mesorectum and the optimal distal clearance margin in situ. Dis Colon Rectum. 2002; 45:744-749.

14. Kanehara \&Co., LTD Tokyo. Japanese Society for Cancer of the Colon and Rectum: Japanese classification of Colorectal Carcinoma, First English Edition.1997.

15. Sternberg A, Mizrahi A, Amar M, Groisman G. Detection of venous invasion in surgical specimens of colorectal carcinoma: the efficacy of various types of tissue blocks. J Clin Pathol. 2006; 59:207-210.

16. Ueno H, Mochizuki H, Hashiguchi Y, Ishiguro M, Miyoshi M, Kajiwara Y, Sato T, Shimazaki H, Hase K. Extramural cancer deposits without nodal structure in colorectal cancer: 
optimal categorization for prognostic staging. Am J Clin Pathol. 2007; 127:287-294.

17. Prabhudesai A, Arif S, Finlayson CJ, Kumar D. Impact of microscopic extranodal tumor deposits on the outcome of patients with rectal cancer. Dis Colon Rectum. 2003; 46:1531-7.

18. Ueno H, Mochizuki H, Tamakuma S. Prognostic significance of extranodal microscopic foci discontinuous with primary lesion in rectal cancer. Dis Colon Rectum. 1998; 41:55-61.
19. Chok KS, Law WL . Prognostic factors affecting survival and recurrence of patients with pT1 and pT2 colorectal cancer. World J Surg. 2007; 31: 1485-90.

20. Harrell FE Jr, Lee KL, Mark DB. Multivariable prognostic models: issues in developing models, evaluating assumptions and adequacy, and measuring and reducing errors. Stat Med. 1996; 15:361-387. 